\title{
Absenteísmo e envelhecimento no contexto ocupacional do Policial Militar
}

\author{
Absenteeism and aging in the military police workforce
}

Daiane Suele Bravo', Pedro Marco Karan Barbosa', Zamir Calamita'

\begin{abstract}
RESUMO | Contexto: A atividade do Policial Militar é desgastante por vivenciar o perigo. As suas condições de trabalho ocasionam danos e favorecem o envelhecimento funcional e o absenteísmo. Objetivos: Identificar as causas do absenteísmo na atividade do Policial Militar e compreender suas condições de trabalho, relacionando-as com o envelhecimento funcional. Métodos: Trata-se de um estudo quanti-qualitativo, retrospectivo e transversal. Os sujeitos de pesquisa foram Policiais Militares do $9^{\circ}$ Batalhão do Interior de São Paulo, do Grupamento de Incêndio, da Polícia Ambiental e do Policiamento Rodoviário, atendidos na Unidade Integrada de Saúde (UIS). Os dados foram coletados dos prontuários ( $\mathrm{n}=285$ ) relativos ao ano de 2012. Uma entrevista semiestruturada foi aplicada para conhecer a percepção dos policiais sobre suas condições de trabalho, relacionando-as com o envelhecimento funcional. Resultados: Verificou-se predomínio de absenteísmo por traumas e problemas ortopédicos. Constataram-se, nas entrevistas, queixas relacionadas ao estresse da profissão como fator preponderante para o envelhecimento funcional. Conclusão: Esta pesquisa possibilitou verificar o absenteísmo e as condições de trabalho dos Policiais Militares atendidos na UIS. Conhecer essas vertentes é relevante para propor ações de saúde. A pesquisa bibliográfica demonstrou carência de estudos nessa área.
\end{abstract}

Palavras-chave I absenteísmo; polícia; envelhecimento; condições de trabalho.

ABSTRACT | Context: The work of the Military Police is exhausting because they experience dangerous situations in performing their duties. Their working conditions cause damage and contribute to functional aging and absenteeism. Objectives: To identify the causes of absenteeism in military police duties and to understand the working conditions related to functional aging. Methods: This is a quantitative-qualitative, retrospective and transversal study. The research subjects were the Military Policemen of a Battalion in São Paulo's countryside, the Fire Combat Team, the Environmental Police and Road Police seen at the Integrated Health Unit (IHU). Data was collected from medical records $(n=285)$ from the year 2012. A semi-structured interview was used to understand the perception of the police force about their working conditions and relating them to functional aging. Results: There was a predominance of absenteeism caused by orthopedic trauma and problems. As regards to the interviews, complaints related to the stress of the job were found to be a major factor for functional aging. Conclusion: This research made it possible to verify the absenteeism and working conditions of the Military Police seen at IHU. Knowing these factors is relevant to proposing health policies. The search for related literature has shown a lack of studies in this area.

Keywords I absenteeism; police; aging; working conditions. 


\section{INTRODUÇÃO}

O ser humano permanece grande parte de sua vida envolto em atividade profissional. Para os Policiais Militares, a atividade profissional caracteriza-se por sofrimento e desgaste, pois convivem com o perigo e com os aspectos criminais do local onde executam suas atividades. Além disso, mantêm o contato com o público em situações adversas e exercem suas atividades em regime de disciplina e hierarquia ${ }^{1}$.

As condições laborais dos policiais podem, com o decorrer do tempo, fragilizar sua saúde, ocasionando altas taxas de absenteísmo, afastamento e levar ao envelhecimento funcional, que é definido como a perda da capacidade para o trabalho e geralmente se faz notar antes do envelhecimento cronológico ${ }^{2}$.

Os termos "absenteísmo", "absentismo" ou "ausentismo" são expressões utilizadas para designar a falta do empregado ao local de trabalho. O termo é originário da palavra "absentismo", que era aplicada aos proprietários rurais que deixavam suas terras para residir nas cidades. No período da Revolução Industrial, esse conceito passou a ser utilizado para designar os profissionais que se ausentavam do serviço ${ }^{3,4}$.

Quick e Lapertosa ${ }^{5}$ subdividem o termo absenteísmo em:

1. absenteísmo voluntário, quando a ausência ocorre por razões particulares não justificadas por doença;

2. absenteísmo por doenças, em que se incluem todas as ausências por doença, excetuando-se os infortúnios profissionais;

3. absenteísmo por patologia profissional, em que se enquadram as ausências por acidentes de trabalho ou doença profissional;

4. absenteísmo legal, compreendido por faltas no serviço amparadas por leis, tais como gestação, nojo, gala, doação de sangue e serviço militar;

5. absenteísmo compulsório, que resulta em impedimento ao trabalho devido à suspensão por prisão ou outro motivo que não permita ao trabalhador chegar ao seu local de trabalhos.

A pesquisa deste artigo concentrou-se no absenteísmo-doença, ou seja, nas ausências ao trabalho que se justificaram pela apresentação de um atestado médico. O absenteísmo por doença revela o estado de saúde do trabalhador e leva a uma reflexão sobre a saúde daquele que trabalha ${ }^{6}$.

Foi objetivo desta pesquisa responder aos questionamentos a seguir:

- Quais as principais causas do absenteísmo (por problemas de saúde) relacionado ao trabalho do Policial Militar no contexto do envelhecimento?

- Qual é a visão do policial sobre o envelhecimento no contexto de seu trabalho?

\section{MÉTODOS}

Com o intuito de conhecer o absenteísmo e o envelhecimento funcional no Policial Militar da região de Marília, São Paulo, foi utilizada uma abordagem quanti-qualitativa, retrospectiva e transversal.

Os sujeitos de pesquisa deste estudo foram os Policiais Militares do $9^{\circ}$ Batalhão de Polícia Militar do Interior ( $\left.9^{\circ} \mathrm{BPM}-\mathrm{I}\right)$, do Grupamento de Incêndio (GI), da Polícia Ambiental (PAmb) e do Policiamento Rodoviário (PRv), os quais são atendidos na Unidade Integrada de Saúde (UIS) da cidade de Marília, sendo um total de 992 policiais; desses, 939 são Praças e 53, Oficiais.

A amostra, na abordagem quantitativa, foi composta de 285 policiais de ambos os sexos. Para obter esse número foi realizado o cálculo do tamanho da amostra (n) necessária para garantir a quantidade ideal de indivíduos ${ }^{7}$.

$\mathrm{O}$ instrumento para coleta dos dados foi organizado a partir do levantamento retrospectivo dos prontuários dos policiais. Essa coleta foi realizada de forma quasi-aleatória, retirando-se um prontuário do arquivo a cada contagem de cinco. $\mathrm{O}$ instrumento para classificação das causas de absenteísmo foi elaborado pelos autores desta pesquisa. As faltas dos policiais foram classificadas de acordo com 15 motivos:

1. Distúrbio emocional não relacionado com dependência química, álcool, etc.;

2. Dependência química, álcool;

3. Traumatismo em serviço ou no quartel, exceto em educação física;

4. Traumatismo durante serviço em educação física;

5. Traumatismo em folga;

6. Problemas ortopédicos crônicos relacionados com serviço (inclusive com educação física); 
7. Problemas ortopédicos crônicos relacionados com traumas fora do serviço;

8. Problemas ortopédicos (dores) sem relação precisa com traumas prévios;

9. Problemas cardiovasculares: hipertensão arterial sistêmica, varizes, etc.;

10. Cefaleia;

11. Distúrbio gastrointestinal;

12. Cólica e infecções renais;

13. Infecção de vias áreas superiores;

14. Conjuntivite;

15. Outras causas.

Para apresentar os resultados, foram utilizados gráficos e tabelas. $\mathrm{Na}$ abordagem quantitativa, as variáveis numéricas de distribuição normal (Gaussiana) foram analisadas por meio de médias e desvio padrão; as variáveis categóricas foram expressas em números absolutos e porcentagens. O cálculo do Odds Ratio (OR) foi utilizado com intervalo de confiança de 95\% (IC95\%) na comparação entre as variáveis analisadas.

No cenário transversal, os dados qualitativos foram coletados por meio de uma entrevista semiestruturada, que oferece um amplo campo de ação ao pesquisador. O número total de entrevistas foi de nove policiais pertencentes ao policiamento ostensivo. Esse número foi obtido em virtude da saturação das falas.

Após a leitura minuciosa do Termo de Consentimento Livre e Esclarecido, explicando os detalhes, o motivo e os objetivos da pesquisa, a entrevista foi gravada em áudio de formato MP3 (MPEG-1/2Audio Layer 3), tendo como questão norteadora: "qual sua compreensão referente às condições de trabalho relacionando-as com o envelhecimento funcional?".

Para atingir o objetivo proposto foram realizadas duas perguntas.

1. “O(A) senhor (a) considera o serviço do Policial Militar como uma atividade profissional mais predisponente ao envelhecimento, quando comparada à de outros segmentos profissionais? Por quê?"

2. "E quais fatores profissionais poderiam favorecer o desenvolvimento de doenças e, consequentemente, o maior número de afastamentos do serviço?"

Os dados qualitativos foram submetidos à técnica de análise de conteúdo que Bardin ${ }^{7}$ conceitua como um "conjunto de instrumentos metodológicos cada vez mais sutis em constante aperfeiçoamento que aplicam a 'discursos' (conteúdos e continentes) extremamente diversificados".

Utilizou-se a modalidade análise temática, na qual, como o próprio nome indica, o conceito central é o tema. Segundo Minayo ${ }^{9}$ a análise temática consiste em descobrir os núcleos de sentido que compõem uma comunicação em que a frequência ou a presença indique alguma coisa para o objeto analítico ${ }^{9}$.

Feita a análise, realizou-se a unificação dos dados quantitativos e qualitativos para propiciar a busca de melhor interpretação e avaliação dos resultados.

O estudo foi aprovado pelo Comitê de Ética em Pesquisas da Faculdade de Medicina de Marília (FAMEMA) sob o número 12686713.8.0000.5413.

Este artigo foi elaborado a partir da dissertação intitulada "Absenteísmo e envelhecimento no contexto ocupacional do Policial Militar da região de Marília-SP”.

\section{RESULTADOS}

Os resultados referem-se a dados coletados junto aos 285 prontuários dos Policiais Militares e ao ano de 2012.

Na Tabela 1, são demonstradas as características sociodemográficas dos Policiais Militares atendidos na UIS.

Tabela 1. Características sociodemográficas dos 285 Policiais Militares avaliados no $9^{\circ}$ Batalhão da Polícia Militar do Estado de São Paulo, na cidade de Marília (SP), no ano de 2012.

\begin{tabular}{l|c|c} 
Características & $n(\%)$ & $\begin{array}{c}\text { Média } \\
\text { (Desvio Padrão) }\end{array}$ \\
\hline Sexo & $261(91,5)$ & - \\
\hline Masculino & $24(8,5)$ & $40,17(+5,5)$ \\
\hline Feminino & - & \\
\hline Idade (em anos) & $32(11,2)$ & \\
\hline Estado civil & $225(79,0)$ & \\
\hline Solteiros & $26(9,1)$ & - \\
\hline Casados & $2(0,7)$ & $18,3(+6,5)$ \\
\hline Separados & - & \\
\hline Viúvo & & \\
\hline $\begin{array}{l}\text { Tempo de profissão } \\
\text { (em anos) }\end{array}$ & & \\
\hline
\end{tabular}


No Quadro 1, evidenciam-se as comparações utilizando o OR, com IC95\%, das causas de absenteísmo com os respectivos dias e as faixas etárias analisadas, demostrando que em algumas faixas etárias houve diferença estatística, quando comparadas com outras.

\section{DISCUSSÃO}

Verificou-se a predominância de Policiais Militares do sexo masculino, sendo que 261 (91,5\%) entre Oficial/Praças eram homens. Um estudo realizado com a Polícia Militar no $3^{\circ}$ Batalhão em Itabaiana, Sergipe, também verificou dados compatíveis aos deste estudo: a categoria da Polícia Militar de Itabaiana ainda é predominantemente masculina, contando com apenas 9\% de mulheres e $91 \%$ de homens, de um total de 179 policiais, demonstrando o predomínio do sexo masculino na profissão ${ }^{10}$.

A presença em maior escala de policiais homens em relação às do sexo feminino é uma realidade nacional. Segundo Calazans ${ }^{11}$, existe uma filosofia de policiamento

Quadro 1. Comparações das causas com os respectivos dias de absenteísmo entre as faixas etárias analisadas dos Policiais Militares no ano de 2012, utilizando o Odds Ratio, com intervalo de confiança de 95\%.

\begin{tabular}{|c|c|c|c|}
\hline \multirow{2}{*}{ Causas de absenteísmo } & \multicolumn{3}{|c|}{ n (\%)/OR (IC95\%) } \\
\hline & 20 a 30 anos & 31 a 40 anos & 41 anos ou mais \\
\hline $\begin{array}{l}\text { Distúrbio emocional não relacionado com depen- } \\
\text { dência química, álcool, etc. }\end{array}$ & - & $5(3,9)$ & - \\
\hline \multirow{2}{*}{$\begin{array}{l}\text { Traumatismo em serviço ou no quartel, exceto em } \\
\text { educação física* }\end{array}$} & \multirow{2}{*}{-} & $19(14,8)$ & $44(31,7)$ \\
\hline & & \multicolumn{2}{|c|}{$0,38(0,21-0,69)$} \\
\hline \multirow{2}{*}{ Traumatismo durante serviço em educação física** } & $10(76,9)$ & $21(16,4)$ & \multirow{2}{*}{-} \\
\hline & 16,9 & DO) & \\
\hline \multirow{2}{*}{ Traumatismo em folga*** } & \multirow{2}{*}{-} & $15(11,7)$ & $14(10,0)$ \\
\hline & & \multicolumn{2}{|c|}{$1,19(0,55-2,56)$} \\
\hline \multirow{2}{*}{$\begin{array}{l}\text { Problemas ortopédicos (dores) sem relação precisa } \\
\text { com traumas prévios* }\end{array}$} & \multirow{2}{*}{-} & $3(2,4)$ & $28(20,2)$ \\
\hline & & \multicolumn{2}{|c|}{$0,10(0,03-0,32)$} \\
\hline Cefaleia & - & $2(1,5)$ & - \\
\hline $\begin{array}{l}\text { Problemas cardiovasculares, Hipertensão arterial sis- } \\
\text { têmica, varizes, etc. }\end{array}$ & - & - & $1(0,8)$ \\
\hline \multirow{3}{*}{ Distúrbio gastrointestinal*** } & \multirow{2}{*}{$3(23,1)$} & \multicolumn{2}{|c|}{$2,51(0,92-6,80)$} \\
\hline & & $13(10,1)$ & \multirow{2}{*}{$6(4,0)$} \\
\hline & 2,6 & 39) & \\
\hline \multirow{2}{*}{ Cólica e infecções renais* } & \multirow{2}{*}{-} & $26(20,3)$ & $1(0,8)$ \\
\hline & & \multicolumn{2}{|c|}{$35,18(4,70-263,50)$} \\
\hline \multirow{2}{*}{ Infecção de vias áreas superiores*** } & \multirow{2}{*}{-} & $3(2,4)$ & $11(8,0)$ \\
\hline & & \multicolumn{2}{|c|}{$0,28(0,08-1,02)$} \\
\hline Conjuntivite & - & $3(2,4 \%)$ & - \\
\hline
\end{tabular}

*Encontrada diferença estatística entre as faixas etárias de 31 a 40 anos e de 41 anos ou mais; **Encontrada diferença estatística entre as faixas etárias de 20 a 30 anos e de 31 a 40 anos; ${ }^{* * *}$ Não encontrada diferença estatística entre as faixas etárias analisadas.

OR: Odds Ratio; IC95\%: intervalo de confiança de $95 \%$. 
movida pelo espírito belicoso do Exército Nacional e por ideologias machistas. Assim, a inserção de mulheres ocorreu de forma limitada e com pouca visibilidade.

A faixa etária predominante entre os Policiais Militares Praças foi de 31 a 40 anos de idade. O número maior de oficiais encontra-se na faixa etária até os 30 anos. Quando comparado com o estudo de Minayo, Souza e Constantino ${ }^{12}$, observou-se que o efetivo maior de policiais Cabos/Soldados estava na faixa etária até 35 anos $(89,2 \%)$; já a faixa etária predominante de Oficial/Suboficial/Sargentos era de 36 a 45 anos (72,1\%). O fato de este estudo apresentar um número expressivo de oficiais na faixa etária de até 30 anos pode ser em decorrência de a entrada desses no efetivo da Polícia Militar ocorrer com, no máximo, 26 anos de idade, exceto se já for integrante da Polícia Militar do Estado de São Paulo. Quanto à inserção dos Praças, pode ocorrer até os 30 anos.

Verificou-se, no estudo, a predominância de policiais militares casados ( $\mathrm{n}=225 ; 79,0 \%)$, seguidos de solteiros $(\mathrm{n}=32 ; 11,2 \%)$, separados $(\mathrm{n}=26 ; 9,1 \%)$ e viúvos $(\mathrm{n}=2$; $0,7 \%)$. No estudo de Minayo, Souza e Constantino ${ }^{12}$, a maioria dos Oficiais/Suboficiais/Sargentos eram casados (81,2\%); o tempo de serviço predominante foi de 11-20 anos, correspondendo ao total de 145 policiais (50,9\%); a média do tempo de serviço foi de 18,3 anos $(+6,5)$, com mediana de 19 anos.

Entre os prontuários analisados, houve ocorrência de 18,60\% de absenteísmo no ano de 2012. O número de absenteísmo $(\mathrm{n}=56)$ foi maior que o número de policiais analisados ( $\mathrm{n}=53$ ) em virtude de, algumas vezes, um determinado policial ter tido mais de um episódio de absenteísmo. Em trabalho realizado por Stein e Reis ${ }^{4}$, com Policiais Militares lotados no $4^{\circ}$ Batalhão de Polícia Militar do Espírito Santo, sediado no Município de Vila Velha, durante o ano de 2010, os resultados apontaram que, no universo de 502 Policiais Militares, mais de 300 se afastaram totalmente do serviço por motivo de doença ou acidente no trabalho. Comparando-os com os sujeitos desta pesquisa, pode-se verificar um número relativamente baixo de absenteísmo dos Policiais Militares da região de Marília. Esses dados não podem, contudo, ser considerados uma realidade para o Estado de São Paulo, já que cada região apresenta suas peculiaridades no serviço.

A faixa etária dos Policiais Militares pode levar à ocorrência do absenteísmo, sendo o traumatismo o mais recorrente.
$\mathrm{Na}$ faixa etária dos 20 a 30 anos, traumatismo durante serviço em educação física correspondeu a 10 dias (76,9\%); dos 31 a 40 anos, traumatismo em serviço ou no quartel, exceto em educação física, apresentou 19 dias (14,8\%); traumatismo durante serviço em educação física, 21 dias (16,4\%); traumatismo em folga, 15 dias (11,7\%); problemas ortopédicos (dores) sem relação precisa com traumas prévios, 3 dias $(2,4 \%)$. Na faixa etária acima de 41 anos, o traumatismo em serviço ou no quartel, exceto em educação física, correspondeu a 44 dias $(31,7 \%)$; traumatismo em folga, a 14 dias (10,0\%); e problemas ortopédicos (dores) sem relação precisa com traumas prévios, a 28 dias (20,2\%).

Estudo realizado na Região Metropolitana de Porto Alegre, Rio Grande do Sul, com o intuito de avaliar a saúde mental e a qualidade de vida de 90 Policiais Civis, constatou que policiais com mais de 10 anos de profissão possuem os maiores prejuízos na qualidade de vida e na saúde mental. Os autores sugerem que o trabalho policial compromete a saúde mental e a qualidade de vida dos sujeitos ${ }^{13}$.

As causas do absenteísmo foram comparadas, com os respectivos dias e as faixas etárias, procurando-se definir se existiram diferenças entre as possíveis causas de absenteísmo em função de cada faixa etária analisada. Considerou-se haver significância estatística quando o valor 1 estivesse fora da abrangência do intervalo de confiança.

Quanto aos traumatismos em serviço ou no quartel, exceto em educação física, constatou-se que Policiais Militares da faixa etária de 31 a 40 anos apresentaram 0,38 vez mais chance de ter um trauma, em relação aos da faixa etária de 41 anos ou mais.

Em relação aos traumatismos durante serviço em educação física, foi observado que os Policiais Militares cuja faixa etária situava-se entre 31 e 40 anos apresentaram 16,98 vezes mais chance (com significância estatística) de sofrer traumas que os da faixa etária compreendida entre os 20 e 30 anos.

Quanto aos problemas ortopédicos (dores) sem relação precisa com traumas prévios, também se constatou diferença estatística entre os grupos etários analisados, sendo que Policiais Militares entre 31 e 40 anos têm 0,10 mais chance de ter problemas ortopédicos (dores), em relação aos da faixa etária de 41 anos ou mais. De maneira inversa, pode-se dizer que policiais com 41 anos ou mais têm 10,00 vezes mais chance de apresentar dores por problemas ortopédicos (sem relação com trauma prévio) que os da faixa etária compreendida entre 31 e 40 anos. 
A segregação dos Policiais Militares de acordo com as faixas etárias permite fazer algumas considerações quanto à carreira policial. Verificou-se que, na faixa etária de $20 \mathrm{a}$ 30 anos, o absenteísmo foi menor em relação aos das outras faixas etárias. Em contrapartida, observou-se que com o decorrer da idade os policiais apresentaram mais absenteísmo, sobretudo por traumatismos em serviço e problemas ortopédicos observados na faixa etária de 41 anos ou mais. Isso leva à seguinte reflexão: será que o fato de ser policial, com todas as peculiaridades da profissão, na abordagem qualitativa, torna-se um agravante para o desenvolvimento de traumas e problemas ortopédicos?

$\mathrm{Na}$ abordagem qualitativa foram identificadas duas temáticas: Alterações Emocionais na profissão de Policial Militar e Desgastes Físicos na profissão de Policial Militar. Foram realizadas nove entrevistas com Policiais Militares, todos do sexo masculino e pertencentes ao policiamento ostensivo, identificados com a letra "P", seguida do número da entrevista.

\section{ALTERAÇÕES EMOCIONAIS NA PROFISSÃO DE POLICIAL MILITAR}

A profissão de Policial Militar é diferenciada. Assim que se forma, o policial faz o juramento perante a corporação assumindo a responsabilidade de respeitar a hierarquia e colocar a própria vida em perigo.

A atividade de Policial Militar caracteriza-se pela atuação em situações agressivas que podem resultar em mortes, além de contar com condições materiais e organizacionais muitas vezes inadequadas ${ }^{14}$.

No âmbito do trabalho, salientam-se alguns aspectos considerados estressantes, como condições físicas inadequadas de trabalho, carga horária excessiva, chefia intransigente e autoritária, entre outros ${ }^{15}$. Embora a profissão de Policial Militar seja considerada como vulnerável ao estresse, verifica-se carência de estudos específicos com esse grupo.

Estudo realizado com a Polícia Militar de Minas Gerais, em que um dos objetivos foi estudar o estresse ocupacional, verificou que a amostra de 1.152 policiais extraída de um contingente de 7.607 constatou a existência de importantes níveis de estresse entre os membros da corporação, que decorrem de elevada insatisfação em relação à instituição ${ }^{16}$.
Outro aspecto evidenciado neste estudo foi a existência de descontentamento em relação à instituição, conforme as falas dos entrevistados:

P3: [...] Muito raramente quem não trabalha na rua que não esteja estressado, em decorrência de mudanças de escalas. Não vou falar desafetos com os superiores, mas algumas situações. A tropa, em geral, está descontente com muitas mudanças e cobranças que, de um tempo pra cá, está muito difícil trabalhar na rua; tanto a gama de leis novas como de aparatos de fiscalização, cobranças. O índice de criminalidade aumentou muito; diminui o efetivo e querem que a gente dê conta dessa situação que cresce a todo dia. Só que diminuiu o efetivo e meios, e cobram para a gente diminuir o índice criminal; mas diminui o efetivo e meios. Não há parcialidade nisso [...]

A atividade desenvolvida pelo Policial Militar é considerada de alto risco, pois atua diariamente em situações de violência e brutalidade, sob forte pressão, arriscando a própria vida, como podemos verificar na fala de P5: “[...] o cara tira a arma da cinta e começa a atirar. Olha a elevação do estresse. É muito constante [...]".

Pesquisa realizada com Policiais Militares de Santa Maria, Rio Grande do Sul, com 75 participantes, verificou que $57,3 \%$ apresentaram sintomatologia de estresse. Segundo a autora, os resultados confirmam que a atividade militar se insere em um contexto de vulnerabilidade e indicam que quanto maior o risco envolvido, menor é a segurança em relação à carreira, sugerindo propostas de intervenção que favoreçam as estratégias de enfrentamento ${ }^{15}$.

Em outro estudo, realizado com aproximadamente 900 Policiais Militares que atuam na região de Marília, São Paulo, a prevalência do estresse foi constatada em $48 \%$ dos policiais; tal informação foi obtida com base na frequência das respostas afirmativas à pergunta existente no questionário sobre a possibilidade de o policial ser ou não estressado ${ }^{17}$.

Quando se reporta novamente à questão norteadora deste trabalho, um dos objetivos era o de identificar aspectos relacionados ao envelhecimento funcional. E, então, observaram-se, em depoimentos dos policiais, relatos que iam ao encontro do interesse de pesquisa. 
Nas falas de P2 e P8, respectivamente, percebe-se que eles acreditam que possuem um envelhecimento acelerado em decorrência de sua atividade laboral, justificando o estresse como fator preponderante:

[...] eu acho. Eu acho não, tenho certeza que o nível de estresse, de cobrança... É, ele acaba causando um envelhecimento maior na profissão nossa, um desgaste maior nosso [...];

[...] essa preocupação, esse estresse do dia a dia, sempre alerta a alguma coisa. Isso vem fazer com o organismo sofrer algum tipo de doença e, consequentemente, um envelhecimento mais rápido [...].

Quanto a este aspecto, ou seja, o envelhecimento funcional, pelo fato de a análise ter se baseado apenas nos relatos dos policiais, isto é, unicamente sobre o prisma qualitativo, poderia caracterizar uma fraqueza do estudo, visto que não foi feita a análise do ponto de vista quantitativo. Para que isso fosse realizado, haveria necessidade de empregar algum tipo de questionário, como o Índice de Capacidade de Trabalho (ICT) ${ }^{18}$. Isso não foi feito porque a intenção primeira era verificar se tal aspecto seria ou não identificado nas falas dos indivíduos estudados.

\section{DESGASTES FÍSICOS NA PROFISSÃO DE POLICIAL MILITAR}

O trabalho é uma atividade que envolve o homem em todas as suas dimensões, exercendo importante papel na construção da subjetividade humana, sendo importante compreender essa relação entre a saúde do trabalhador e o trabalho. As relações laborais podem proporcionar ao indivíduo bem-estar físico e mental, como também causar estresse e sofrimento ${ }^{19}$.

$\mathrm{O}$ trabalho realizado por Minayo, Assis e Oliveira ${ }^{20}$, em que o intuito foi analisar o envelhecimento físico e mental de Policiais Militares e Civis do Estado do Rio de Janeiro, segundo condições de trabalho e atividades profissionais, contou com 1.458 Policiais Civis e 1.108 Policiais Militares, com uma abordagem quanti-qualitativa. Verificou-se que muitos são acometidos por doenças que afetam a população em geral, por causa do contato muito próximo e também pelo contato com presos.
Essa realidade vem ao encontro da percebida neste estudo. Observou-se, nas falas dos sujeitos, que eles se julgam mais expostos a fatores desencadeantes de doenças de pele, entre outras enfermidades, conforme ressaltado na fala do policial $\mathrm{P} 4$ :

[...] o policial tem que ir nas casas, onde as pessoas passam e lugares onde supostamente o traficante esconde a droga. Eu falo isso da minha rotina diária, porque a gente entra em lugar que tem esgoto a céu aberto e entra dentro do esgoto propriamente dito. Tipo, por exemplo, (cita a vila) a pessoa que vai esconder o entorpecente ela vai não esconder ali onde todo mundo passa, ela vai entrar para dentro mais a fundo onde é inóspito. Realmente que ninguém, em sã consciência, entraria para esconder. A gente entra, pisa no barro e, tipo assim, você nota problemas de pele $[. .$.

Outros fatores relevantes são os agravos osteomusculares; pois, segundo Minayo, Assis e Oliveira ${ }^{20}$, entre os Policiais Militares são predominantes as dores no pescoço, nas costas, na coluna, torção ou luxação de articulações e outros agravos relativos a músculos. Segundo essas pesquisadoras, a maioria dos pedidos de afastamentos é em decorrência de problemas de ortopedia, inerentes à natureza da profissão que exige saltar, correr, e expõe a outras situações que podem ocasionar traumas físicos ${ }^{20}$. Esse dado vem ao encontro deste estudo, que revelou, na abordagem quantitativa, uma expressão maior de causas ortopédicas. Essas queixas também estão nítidas na abordagem qualitativa, conforme as falas dos entrevistados a seguir:

P2: [...] é o próprio fardamento. Colete tem que usar, mas é um negócio que desgasta bastante o policial; o cinto pesado, arma... é... coisas que favorecem, sim, a desenvolvimento de doenças. Vejo bastante policiais com problemas de dor nas costas, dor nas pernas, hérnia de disco, o que tô lembrando agora. É, seria isso aí [...]

P3: [...] Desgaste físico é uma hora por inércia e outra por muita atividade física; inércia, porque muitas vezes a gente tá na viatura sentado no patrulhamento. Fica oito horas s entado na viatura, não faz 
nada, vamos dizer assim; em outros, você tá no meio do mato, você tá escalando, fazendo muita atividade sem um pré-aquecimento [...]

A escala de trabalho do Policial Militar pode acarretar, ao longo do tempo, consequências para a saúde, pois assim como em outros segmentos profissionais, como ocorre na área da saúde, por exemplo, sua jornada de trabalho é realizada em regime de plantões. $\mathrm{O}$ regime de trabalho do Policial Militar é organizado por meio de escalas, podendo ser de 6 horas de trabalho por 18 de folga; 12 por 48 horas; 12 por 36 horas; ou até mesmo 24 por 72 horas. Conforme P4:

[...] irregularidade de escala; por exemplo, hoje tô trabalhando de manhã, hoje eu acordei mais cedo. No próximo serviço, eu vou passar a noite, o relógio biológico não se acerta. A escala é variável, isso também é um fator de desgaste físico $[. .$.

Outro fator relevante quanto ao serviço do Policial Militar é o local onde executa seus serviços, além de manter contato direto com a população e de combater a criminalidade. A exemplo deste relato de $\mathrm{P} 4$, o policial trabalha em condições adversas; muitas vezes na chuva, no frio e exposto ao sol, exposição que pode acarretar danos à saúde:

[...] eu trabalhei na cavalaria... eu trabalhei 20 anos na cavalaria, 20 anos se expondo ao sol, 20 anos se expondo a tudo, porque no cavalo você não tem nem a proteção do teto da viatura. Então é frio, é chuva... eu falo, já passei por tudo isso e é penante [...]

Os policiais deste estudo apresentaram queixas quanto à exposição ambiental, pois em sua rotina diária exercem sua atividade sob condições climáticas nem sempre favoráveis, seja sob sol ou sob chuva, durante as 24 horas do dia. A Polícia Militar do Estado de São Paulo fornece protetores solares, porém não se sabe qual sua adesão pelos militares.

\section{CONCLUSÕES}

Este estudo possibilitou conhecer o absenteísmo por doença nos Policiais Militares do $9^{\circ}$ Batalhão da Polícia
Militar, do Grupamento de Incêndio (GI), da Polícia Ambiental (PAmb) e do Policiamento Rodoviário (PRv), os quais são atendidos na UIS, e verificar a sua percepção quanto ao envelhecimento funcional. Foram coletados dados junto aos prontuários de 285 policiais, no período de janeiro a dezembro de 2012, e as entrevistas foram realizadas com a finalidade de conhecer a percepção dos policiais quanto à sua profissão e ao envelhecimento.

As peculiaridades do trabalho da Polícia Militar parecem favorecer diretamente o sofrimento e o envelhecimento desse segmento profissional e também propiciar o absenteísmo-doença. Existe a tensão do exercício, o risco da profissão, as jornadas irregulares, além do regime de disciplina e hierarquia. Esses fatores, ao longo do tempo, acarretam consequências na vida do policial, conforme evidenciado nas falas dos policiais que julgam sua atividade desgastante e nas quais o nível de estresse se faz presente.

Dentro da pesquisa, na abordagem quantitativa, verificouse que a maioria das causas de absenteísmo acontece em decorrência de traumas e problemas ortopédicos, independentemente de esse traumatismo ocorrer em serviço ou no quartel, durante serviço em educação física, em folga, e problemas ortopédicos (dores) sem relação precisa com traumas prévios.

Foram constatadas, na abordagem qualitativa, nas falas dos entrevistados, queixas que não tiveram predominância na abordagem quantitativa, como o fator estresse da profissão. Essa informação remete à reflexão de que muitos policiais podem estar trabalhando com nível acentuado de estresse e não solicitam atendimento médico, continuando no exercício da profissão.

Atualmente, no cenário de pesquisa deste estudo, os policiais são atendidos por uma medicina preventiva. No mês do aniversário é realizada inspeção de saúde, em que são solicitados alguns exames aos policiais. Contudo, seriam necessárias também novas abordagens focando nas questões ortopédicas e emocionais, de maneira profilática, e uma atuação multiprofissional para atender esses policiais, englobando, além do atendimento médico, fisioterapeutas, terapeutas ocupacionais e psicólogos.

Em suma, poder-se-ia fomentar as pesquisas em outros batalhões, para permitir uma comparação entre os resultados obtidos neste estudo, as quais poderão confirmar, ampliar ou revisar essas conclusões. 


\section{REFERÊNCIAS}

1. Oliveira KL, Santos LM. [Internet] Percepção da saúde mental em policiais militares da força tática e de rua [acesso em 2014 jul 28]. Sociologias. 2010;12(25):224-50. Disponível em: <http://www.scielo. $\mathrm{br} / \mathrm{pdf} / \mathrm{soc} / \mathrm{v} 12 \mathrm{n} 25 / 09 . p d f>$

2. Bellusci SM, Fischer FM. Envelhecimento funcional e condições de trabalho em servidores forenses. Rev Saúde Pública. 1999;33(6):602-9.

3. Nascimento GM. [Internet] Estudo do absenteísmo dos trabalhadores de enfermagem em uma unidade básica e distrital de saúde do município de Ribeirão Preto - SP [acesso em 2014 maio 16]. [Dissertação de Mestrado]. Ribeirão Preto (SP): Universidade de São Paulo, Escola de Enfermagem de Ribeirão Preto; 2003. Disponível em: <http://www.teses.usp.br/teses/disponiveis/22/22132/ tde-21052004-110529/>

4. Stein AC, Reis AMS. [Internet] O absenteísmo por dispensa médica e os prejuízos para gestão policial militar: um estudo de caso do $4^{\circ}$ BPM [acesso em 2014 set 15]. Disponível em: <http://www.pm.es. gov.br/download/reistaprelecao/Revista_Prelecao_Edicao_11. pdf>.

5. Quick TC, Lapertosa JB. Análise do absenteísmo em usina siderúrgica. Rev Bras Saúde Ocup. 1982;10(40):62-7.

6. Kivimäki M, Head J, Ferrie JE, Shipley MJ, Vahtera J, Marmot MG. Sickness absence as a global measure of health: evidence from mortality in the Whitehall II prospective cohort study. BMJ. 2003;327(7411):364.

7. Castro AA, Clark OAC. [Internet] Planejamento da pesquisa [acesso em 2014 jun 15]. Disponível em: <http://www.decisaoclinica.com/ planejamento/pdf/lv4_01_planeja.pdf>

8. Bardin L. Análise de conteúdo. São Paulo: Edições 70; 2012.

9. Minayo MCS. O desafio do conhecimento: pesquisa qualitativa em saúde. 13a ed. São Paulo: Hucitec; 2013.

10. Lima SR, Castro APS, Cruz MHS. [Internet] Relações de gênero no trabalho: um estudo no $3^{\circ}$ Batalhão da Polícia Militar (Itabaiana/ SE) [acesso em 2014 jun 15]. Rev Fórum Identidades. 2010;7(4):14557. Disponível em: <http://200.17.141.110/periodicos/revista_forum_ identidades/revistas/ARQ_FORUM_IND_7/FORUM_V7_08.pdf>

11. Calazans ME. Mulheres no policiamento ostensivo e a perspectiva de uma segurança cidadã. São Paulo Perspect. 2004;18(1):142-50.
12. Minayo MCS, Souza ER, Constantino P, coordenadoras. Missão prevenir e proteger: condições de vida, trabalho e saúde dos policiais militares do Rio de Janeiro. Rio de Janeiro: Fiocruz; 2008.

13. Wagner LC, Stankievich RAP, Pedroso F. Saúde mental e qualidade de vida de policiais civis da região metropolitana de Porto Alegre. Rev Bras Med Trab. 2012;10(2):64-71.

14. Rodrigues MAM. [Internet] Trajetória institucional de policiais militares afastados do trabalho por transtornos mentais no Espírito Santo [acesso em 2013 dez 16]. [Dissertação de Mestrado]. Vitória (ES): Escola Superior de Ciências da Santa Casa de Misericórdia de Vitória; 2012. Disponível em: <http://www.emescam.br/ arquivos/pos/stricto/dissertacoes/50_MARIA_ANGELA_MOURA_ RODRIGUES.pdf>

15. Oliveira PLM, Bardagi MP. Estresse e comprometimento com a carreira em policiais militares. Bol Psicol. 2009;59(131):153-66.

16. Moraes LFR, Pereira LZ, Lopes HEG, Rocha DB, Ferreira SAA, Portes PCP. [Internet] Estresse e qualidade de vida no trabalho na Polícia Militar do Estado de Minas [acesso em 2014 nov 24]. Anais do $25^{\circ}$ Encontro da Associação Nacional de Pós-Graduação e Pesquisa em Administração; 2001 set 16-19; Campinas, SP. Rio de Janeiro: ANPAD; 2001. Disponível em: <http://www.anpad.org.br/admin/ pdf/enanpad2001-grt-359.pdf>

17. Calamita Z, Silva Filho CR, Capputti PF. Fatores de risco para doenças cardiovasculares no policial militar. Rev Bras Med Trab. 2010;8(1):39-45

18. Tuomi K, Ilmarinen J, Jahkola A, Katajarinne L, Tulkki A. Índice de capacidade para o trabalho. São Carlos (SP): EdUFSCar; 1997.

19. Glanzner $\mathrm{CH}$, Olschowsky A, Kantorski LP. O trabalho como fonte de prazer: avaliação da equipe de um Centro de Atenção Psicossocial. Rev Esc Enferm USP. 2011;45(3):716-21.

20. Minayo MCS, Assis SG, Oliveira RVC. Impacto das atividades profissionais na saúde física e mental dos policiais civis e militares do Rio de Janeiro (RJ, Brasil). Ciênc Saúde Coletiva. 2011;16(4):2199-209.

Endereço para correspondência: Daiane Suele Bravo - Faculdade de Medicina de Marília (FAMEMA), Setor de Pós-Graduação - Rua Monte Carmelo, 800, Fragata CEP: 17519-030 - Marília (SP), Brasil - E-mail: daianebravo@hotmail.com 